\title{
Tecnologias e precariedades na pandemia: a área de CALL no Brasil
}

\author{
Alan Ricardo COSTA (1) \\ Universidade de Santa Cruz do Sul (UNISC) \\ Peterson Luiz Oliveira da SILVA 『 \\ Centro Universitário Internacional (UNINTER)
}

○

OPEN ACCESS

EDITADO POR

Raquel Freitag

AVALIADO POR

Noádia Silva

SOBRE OS AUTORES

Alan Ricardo Costa

Contribuiu com

Peterson Luiz Oliveira da Silva.

Papéis: escrita - rascunho

original.

Peterson Luiz Oliveira da Silva Contribuiu com Alan Ricardo Costa. Papéis: escrita - análise e edição

DATAS

Recebido: 02/07/2020

Aceito: 08/08/2020

Publicado: 19/08/2020

COMO CITAR

Costa, A. R.; Silva, P. L. O.

(2020).

Tecnologias e precariedades na pandemia: a área de CALL no Brasil. Revista da Abralin, v. 19,

n. 2, p. 1-5, 2020.
RESUMO

No presente texto, resenhamos a palestra ministrada por Ana Elisa Ribeiro, intitulada Educação e tecnologias digitais: ciclos de precariedade diante da pandemia, que ocorreu em 25 de junho de 2020, como parte das atividades do evento Abralin ao Vivo - linguists online. Em sua fala, a referida pesquisadora denuncia e problematiza aspectos imbricados nos ciclos de precariedade com os quais muitos professores de línguas - familiarizados ou não com o ensino online - já lidavam antes e seguem lidando de forma mais perceptível agora: infraestrutura precária, sinal de internet de baixa qualidade, falta de formação docente e capacitação específica para tal trabalho (sopesando o ineditismo da situação de pandemia), etc. A partir desse olhar sobre o presente, Ribeiro nos possibilita pensar muitas questões para o futuro do ensino de línguas mediado por computador e/ou tecnologias digitais.

\section{RESUMEN}

En el presente texto, reseñamos la conferencia impartida por Ana Elisa Ribeiro, titulada Educación y tecnologías digitales: ciclos de precariedad delante de la pandemia, realizada el 25 de junio de 2020, como parte de las actividades del evento Abralin en Vivo. En su discurso, la investigadora mencionada denuncia y problematiza aspectos imbricados en los ciclos de precariedad que muchos profesores de lenguas, que ya conocían o no la enseñanza en línea, han tratado antes y continúan lidiando de manera más notable ahora: infraestructura precaria, señal de internet de baja calidad, 


\section{REVISTA DA ABRALIN}

falta de capacitación docente específica para dicho trabajo (considerando la naturaleza sin precedentes de la situación de pandemia), etc. A partir de esta mirada en el presente, Ribeiro nos permite pensar en muchas preguntas para el futuro de la enseñanza de lenguas mediada por computadora y/o tecnologías digitales.

\section{PALAVRAS-CHAVE}

Tecnologias digitais. Ensino online. Pandemia.

\section{PALABRAS CLAVE}

Tecnologías digitales. Enseñanza en línea. Pandemia.

Em julho de 2020, Ana Elisa Ribeiro ${ }^{1}$, com seus mais de vinte anos de atuação profissional e pesquisa sobre tecnologias digitais, proferiu palestra em que problematizou as precariedades do ensino online antes e durante o contexto de pandemia global que atualmente vivemos em função do Coronavírus SARS-CoV-2 (Covid-19). Em sua fala, a palestrante não aludiu diretamente à área de Computer-Assisted Language Learning (CALL), ou Ensino de Línguas Mediado por Computador (REIS, 2010), mas muitas das suas discussões estão em sinergia com as tendências da área no Brasil, razão pela qual a associação parece oportuna.

CALL é uma sigla consolidada nas últimas décadas para nomear uma seara cujo escopo é a investigação dos processos de ensino de línguas mediados por computador (inicialmente) ou por tecnologias digitais de modo geral (mais atualmente ${ }^{2}$ ). Leffa (2006, p. 17), uma autoridade nacional sobre o tema, explica que CALL é "provavelmente a área mais interdisciplinar de uma área essencialmente interdisciplinar" como a Linguística Aplicada (LA). Consideramos profícua a associação entre a palestra de Ribeiro e CALL, pois, em sua conferência, a autora abarca tópicos pertinentes a dois grupos de docentes/pesquisadores: (1) aqueles familiarizados com o campo; e (2) aqueles que desconhecem a área, mas que podem valer-se dela para aprimorar suas práticas educacionais no ensino remoto, implementado de forma urgente por força das circunstâncias.

Trataremos primeiramente de questões mais pertinentes aos estudiosos de CALL, priorizando popularizar as discussões sobre tecnologias entre os pares docentes, bem como fez a própria Ribeiro. Nesse quesito, destacamos: muitas das questões apresentadas pela conferencista são dignas de nota

\footnotetext{
1 Doutora em Linguística Aplicada (Linguagem e Tecnologia) e Mestra em Estudos Linguísticos (Cognição, Linguagem e Cultura) pela Universidade Federal de Minas Gerais (UFMG). Possui Pós-Doutorado em Comunicação (PUC-Minas, 2009-2010), em Linguística Aplicada (Instituto de Estudos de Linguagem da Unicamp, 2011-2013) e em Estudos Literários (Pós-Lit UFMG, 2015-2016).

2 Daí, inclusive, a ascensão recente da sigla MALL, de Mobile-Assisted Language Learning. Nesta resenha, optamos pela sigla CALL mais em função do seu histórico uso em periódicos e livros da área, mas subsumindo que ela abarca tecnologias de modo geral: computador, aparelhos móveis etc.
} 


\section{REVISTA DA ABRALIN}

não necessariamente por um ineditismo na área (salvo aquelas que versam especificamente sobre a pandemia que vivemos), mas por levar aos colegas professores tópicos importantes de CALL. Passamos à discussão de quatro desses tópicos.

O primeiro deles diz respeito à importância de um alinhamento entre a popularização de tecnologias digitais e a formação docente. Esses dois elementos são constitutivos de CALL: a área só existe se houver sintonia entre tecnologias digitais e reflexão constante sobre os educadores que estamos formando. Evidentemente, pode-se argumentar que não somos tecnológicos só no presente - o humano é fundamentalmente tecnológico desde os primeiros usos do fogo, da pedra e da língua -, mas, sim, temos hoje tecnologias digitais, cuja complexidade não pode ser comparada às tecnologias de outrora. De igual forma, pode-se argumentar também que nos formamos professores continuamente, constantemente, inclusive apesar das tecnologias digitais, mas espera-se que essa formação seja pensada e efetivada sem desconsiderá-las, haja vista seu potencial nos processos educacionais. Quanto a esse aspecto, Ribeiro contribui para a visualização das conexões entre políticas públicas, avanços tecnológicos, papel das universidades e formação de professores no viés dos letramentos digitais.

O segundo aspecto debatido por Ribeiro, importante para o campo de CALL, é a denúncia das precariedades com as quais lidamos na educação. Partindo de uma noção geral de precariedade (tudo aquilo que não funciona de maneira adequada), a palestrante nos permite olhar para a crise da pandemia não como causadora de todas as crises, mas como uma que se soma às outras que já existiam, como a crise da educação, que é também tecnológica. Ambientes Virtuais de Aprendizagem (AVA) sem estrutura adequada, sinal de internet precário, equipamentos obsoletos... todos esses são indicativos de que tínhamos um ciclo de precariedades antes, estamos tendo outro agora, que atinge outros pontos, e talvez tenhamos outros ciclos depois, isto é, nesse futuro absolutamente imprevisível. Aos pesquisadores de CALL, cabe esse lembrete constante sobre as precariedades, pois aceitamos (quase que naturalizamos) conviver com elas.

Um terceiro aspecto válido é a revisão/autocrítica de nossas posturas enquanto pesquisadores de CALL. Ribeiro observou que o momento atual pode servir para o repensar de nossas práticas e escritas acadêmicas sobre as tecnologias digitais. Com efeito, aquilo que foi escrito e publicado antigamente pode ficar datado, e nenhum texto (principalmente o científico) deve ser lido de forma anacrônica. Ainda assim, todos que pesquisam e publicam sobre tecnologias podem, a partir de então, rever a ideia subsumida de que "todo mundo tem acesso" às tecnologias digitais. A desigualdade social, tão aguda no Brasil, não era necessariamente negligenciada em CALL, mas talvez tenhamos que lançar mais luz sobre ela. Enquanto pesquisadores, podemos (devemos) atuar de forma mais direta no combate às desigualdades atreladas à inclusão tecnológica, sobretudo em termos de registro e denúncia.

Uma quarta e última questão levantada por Ribeiro e pertinente à seara de CALL refere-se a seus principais compositores: professores de Línguas Estrangeiras (LE). Partindo de suas percepções, a palestrante expôs a sensação de que docentes de Língua Materna (LM) ainda não fazem usos de tecnologias digitais de forma geral como os colegas de LE. Isso se dá muito possivelmente por razões 


\section{REVISTA DA ABRALIN}

históricas: a Abordagem Comunicativa (LEFFA, 1988), com seus pressupostos metodológicos, levou professores de LE a um ensino mais atrelado às tecnologias digitais, tendência que se mantêm na atualidade. Portanto, há a demanda hoje por uma comunidade docente mais unida quanto às práticas tecnológicas bem sucedidas de ensino de línguas, sem, com isso, ignorar as especificidades do ensino de LM ou de LE.

Elencados esses tópicos voltados aos estudiosos de CALL, passamos aos aspectos mais direcionados aos docentes que ainda não pertencem à área. Todo professor de línguas ainda não familiarizado com CALL pode sentir-se, desde já, convidado a integrar essa comunidade. Primeiramente, porque as portas e fronteiras de CALL nunca estão fechadas, se é que elas existem. Em segundo lugar, porque o contexto demanda dos educadores adesão ao movimento constante de olhar crítico sobre as tecnologias digitais. Em terceiro lugar, porque, apesar de não podermos afirmar como o futuro será, é presumível que o computador e as tecnologias digitais não deixarão de exercer papel importante na sociedade, como já exerciam muito antes da pandemia.

Aos que não são familiarizados com CALL no Brasil, as contribuições de Ribeiro são ainda mais elogiosas: o discurso da palestrante foi, em um mesmo tempo, elucidativo e tranquilizador. Elucidativo por explicar algumas questões pertinentes ao cenário atual; e tranquilizador por tirar das costas de professores de línguas culpas e angústias.

Entre outras elucidações, Ribeiro explicou, por exemplo, que ensino remoto e Educação a Distância (EaD) não são iguais. A EaD é uma modalidade já consagrada, com metodologia própria e capacitação docente para tal. O ensino remoto, como está sendo convencionado chamar, é inédito, ninguém estava capacitado para ele. Outra explicação pertinente é com relação à terminologia "adaptação" ou "transição" para o ensino remoto. Ainda não definimos qual termo usar, mas, independentemente da nomenclatura eleita, tal processo deve ser pensado/implementado por e entre professores, não por representantes políticos aos quais cabem críticas, principalmente pelo descaso com as ações de popularização de tecnologias e formação docente para tal fim, antes e durante a pandemia.

Quanto às tranquilizações, Ribeiro reforçou: este é um momento ímpar, sobre o qual não temos responsabilidade. Baixemos, portanto, nossa autoexigência. Os ciclos de precarização abrangem os "acessos negados", os "acessos negligenciados" e as "desconexões criminosas" (aquelas feitas de má fé, no sentido de ser criminoso o descaso e o abandono de uma determinada comunidade ou grupo social que precisa dessas conexões). E, mesmo nesse cenário perverso, os professores estão se saindo muito bem. Há casos de reclamações de algumas escolas, mas elas também estão se saindo bem de modo geral, com os recursos e meios que têm, mesmo depois de décadas de precariedades. Vários professores trabalham sem escritório, sem aparelhos tecnológicos adequados, sem internet de qualidade, e ainda assim contribuem para que a educação se mantenha durante a pandemia.

A palestra de Ribeiro, além de atender a uma necessidade atual - o pensar sobre o ensino remoto emergencial -, esboçou reflexões pertinentes entre o que era normal no fazer docente e o "novo normal", designação (discutível) para aquilo que virá pós-pandemia. Questionando "O que vai ser aprendido?" e "O que vai ser abandonado?" desse contexto vivenciado, e referenciando uma questão que consta na Dissertação de Mestrado de Leite (2013), Ribeiro destaca que, para alguns professores, 


\section{REVISTA DA ABRALIN}

uma aula de língua normal, até então, era uma aula sem tecnologias digitais. Uma aula anormal, em contrapartida, era aquela que contava com tais recursos. O "novo normal", nesse sentido, será com ou sem tecnologias digitais? Apesar das dúvidas, vale pensar que o futuro em grande medida será composto por aquilo que a comunidade de CALL (espera-se que composta com adesão da classe docente em geral) pensar, propor e efetivar no presente. Nossas questões sobre o amanhã são muitas, razão pela qual a palestra de Ribeiro mostrou-se extremamente importante ao hoje.

\section{REFERÊNCIAS}

EDUCAÇÃO e tecnologias digitais: ciclos da precariedade diante da pandemia. Conferência apresentada por Ana Elisa Ribeiro. [S.l., s.n], 2020. 1 vídeo (1h 33min 35s). Publicado pelo canal da Associação Brasileira de Linguística. Disponível em: <https://www.youtube.com/watch?v=-lfTZT7oFI\&t=1115s >. Acesso em: 27 jun 2020.

LEFFA, Vilson José. A aprendizagem de línguas mediada por computador. In: LEFFA, Vilson José. (Org.) Pesquisa em Linguística Aplicada: temas e métodos. Pelotas: Educat, 2006, p.11-36.

LEFFA, Vilson José. Metodologia do ensino de línguas. In: BOHN, Hilário Inácio; VANDRESEN, Paulino. Tópicos em Linguística Aplicada: O ensino de línguas estrangeiras. Florianópolis: Ed. da UFSC, 1988. p. 211-236. Disponível em: <http://www.leffa.pro.br/textos/trabalhos/Metodologia_ensino_linguas.pdf>. Acesso em: 27 jun. 2020.

LEITE, Carla Geralda. Vai ter que ser uma aula normal? Letramento digital, formação de professores e tecnologias na escola. 2013. Dissertação (Mestrado em Estudos de Linguagens) - Centro Federal de Educação Tecnológica de Minas Gerais, Minas Gerais, 2013.

REIS, Susana Cristina dos. Do discurso à prática: textualização de pesquisas sobre ensino de inglês mediado por computador. 2010. Tese (Doutorado em Letras) - Centro de Artes e Letras, Universidade Federal de Santa Maria, Rio Grande do Sul. 2010. 